\title{
The Influence of Content Schema on L2 Learners' Reading Comprehension: Evidence from Chinese Learners of English
}

\author{
Jingyi Hu \\ Hunan University, Changsha, Hunan Province 410006, China
}

\begin{abstract}
Reading plays a significant role in language learning and information communication. This study investigated the influence of content schema on Chinese English learners' reading comprehension. Participants were 20 freshmen with the same English proficiency. Schema theory was adopted as the theoretical foundation. The results showed that: (1) Content schemata enhanced L2 learners' reading comprehension performance; (2) Content schemata had a positive impact on the comprehension of expository passages and little effect on that of narrative passages; (3) Proficiency level correlated positively with reading comprehension performance. But the insufficiency of language knowledge could be supplemented by relevant schemata. Based on the above, some suggestions are provided for the teaching and learning of English.
\end{abstract}

Keywords: Reading comprehension; Content Schema; Schema theory; Chinese English learners.

(c) (1) CC BY: Creative Commons Attribution License 4.0

\section{Introduction}

Reading is considered as one of the receptive forms of written language. Carrel (1981), proposed that reading should be given top priority among all the basic skills including listening, speaking, reading and writing. For L2 learners, to read well in second languages is important, for reading is an efficient way of input (Johnson, 1981).

Reading is defined as a meaningful explanation of the written or printed symbols (Harris and Sipay, 1975). Traditional reading concept holds that meaning exists in texts to be read rather than in readers' mind. If a reader has difficulties in comprehending a text, it must be the vocabulary or the grammar in the text that causes the unexpected result. However, it is widely noticed that readers cannot comprehend the intended meaning of the text even when they are able to understand every word and every sentence in the text.

This phenomenon has aroused general attention of linguists (Caroline, 1996; Schmid-Rinehart, 1994). To give a reasonable explanation, Carrel and Eisterhold (1983), proposed Schema Theory, which lays emphasis on the role of schemata in reading comprehension. According to Afflerbach (1990), the positive effects of schemata on reading comprehension exist only in first language (hereafter, L1) readers. Carrel (1984). Also proposed that the reading mode of second language (hereafter, L2) readers was different from that of L1 readers. Therefore, restricted by their native language, it is hard for $\mathrm{L} 2$ readers to make use of schemata.

However, few studies are conducted to investigate the influence of schemata, especially content schema, on Chinese English learners' reading comprehension. It remains unknown that whether Chinese English learners have the ability to utilize content schema while reading. It is of great significance to figure out this question for it may improve Chinese English learners' reading comprehension ability wholly. Hence, the present study aims to investigate the role of content schema in Chinese English learners' reading comprehension performance and to provide some pedagogical suggestions according to our findings.

\subsection{The Interactive Model of Reading Comprehension}

Proposed by Rumelhart and Ortony (1977), the interactive model considers reading process as an interaction between information offered by bottom-up decoding and obtained through top-down analysis. In this process, visual symbols, various levels of language knowledge and different kinds of cognitive activities are involved. While reading, the reader's brain deals with the visual information obtained from the phonological to lexicological, to syntactic and then to semantic levels. In the meantime, he utilizes his language knowledge and prior background knowledge to deal with the visual information and bring out expectations.

Later, Stanovich (1980), put forward an interactive-compensatory model as a supplement of the interactive model. It states that a deficiency in any knowledge leads to a heavier dependence on other knowledge in spite of its level in the processing hierarchy. For example, if a reader hasn't got enough information from the text but knows relevant background information about the text in advance, top-down model may be applied for the compensation. All in all, the interactive model requires readers to have necessary language knowledge as well as adequate schemata (i.e. background knowledge).

\subsection{Schema}

The term "schema" has been defined by many linguists (Barlett, 1932; Reber and Reber, 2001; Widdowson, 1983). Piaget (1926), One definition made by Piaget (1926) is a schema is a storage unit of knowledge in brain. The 
total of schemata is equal to the sum of one man's knowledge. There are different types of schemata such as linguistic schema, formal (textual) schema and strategic schema content schema and so forth.

Content schema, which is also called topic schema, concerns the topic of the text. It demands that readers have relative background knowledge so that they can have better understandings of the text, especially the text with an unfamiliar topic. Background knowledge consists of life experience, scientific knowledge, cultural knowledge, social knowledge and so forth. Different readers have different background knowledge since it is closely related to their living and educational experiences.

\subsection{Schema Theory}

Schema theory was proposed by Carrel and Eisterhold in 1983 on the basis of interactive model. It describes how the knowledge people acquired is stored in brain and how it is combined into an integrated system of information. According to schema theory, meaning exists in the form of schemata in human brain rather than in the text, whether it is a spoken text or a written one. Meaning is dependent on the activation and utilization of schemata in brain during the reading process. When meeting something new, people always associate it with things that are already known. Hence, the reader who has more schemata tends to have a better comprehension of a text in an easier way. During reading process, word recognition (bottom-up model) and schemata (top-down model) work simultaneously. The failure of comprehension may be caused not only by insufficient clues from the text but also the lack of relevant schemata. Possession of abundant schemata is vital to reading comprehension.

Based on the above, the present study aims to investigate whether content schemata have influence on Chinese English learners' reading comprehension performance. Three research questions are thus formed: (1) Does content schema affect Chinese English learners' reading comprehension? (2) Does content schema have different effects on different text types? If it does, what are the different effects? (3) Is reading comprehension performance related to language proficiency? Can content schema make up the insufficiency of language knowledge in reading comprehension?

Based on schema theory, three hypotheses are also formed: (1) Content schema contributes to Chinese English learners' reading comprehension; (2) Content schema has different effects on different text types; (3) Reading comprehension performance is related to language proficiency, but the insufficiency of language knowledge can be made up by background knowledge.

\section{Methods}

\subsection{Participants}

Twenty freshmen (10 males and 10 females; age range: $17-19, \mathrm{M}=17.9, \mathrm{SD}=0.76)$ were recruited in this study. They were divided into two groups including an experimental group and a control group randomly, with 10 students ( 5 males and 5 females) in each group. To remove the interference of language proficiency, we collected their scores in National Matriculation English Test. The result of Independent Samples T-test showed that these two groups with the same English level (sig.= 0.956) were suitable for this study. Informed consent was obtained from all participants. All participants were paid after finishing the experiment.

\subsection{Materials}

In this research, a reading comprehension test and a questionnaire were adopted as instruments in this research.

The reading comprehension test was used as the primary tool. First, we selected four English reading materials including two expository passages and two narrative passages. The expository passages were about black box and Otitis Media respectively. And the narrative passages described the author's experience in the jungle and the author's wonderful memory of flying kites with dearest people respectively. Every passage was followed by five choice questions concerning the contents of the passage. The reason for using choice questions was to avoid the subjectivity in scoring. The topic of every passage was unfamiliar to participants and the difficulty of every passage is above their English proficiency level. In this case, they could not only rely on the strategy of bottom-up model.

Then four Chinese reading materials were selected to provide background information for the experimental group. Their topics are the same as those of English reading materials but the contents are different. Another four Chinese reading materials with irrelevant topics were provided for the control group. These reading materials are presented in Chinese so that participants can have a comprehensive understanding and a deep memory of their topics and contents.

Besides, we designed a questionnaire, aiming to investigate participants' opinions towards reading comprehension and their actual reading processes. The questionnaire contained three questions. Each question provided participants with three possible alternatives. Participants were required to choose the most appropriate answer from those three ones.

\subsection{Procedures}

There were three sections on the test paper. Participants were required to finish them in sequence. The first section was Chinese materials reading. To make sure that participants read these materials carefully, they were asked to divide every passage into paragraphs according to its meaning. The next section was English reading comprehension. Four passages were included. Participants were required to read these passages and choose the most appropriate answer to every question. After that, they should to finish the questionnaire, i.e. to choose the most suitable answer to each question in a practical and realistic way. 
To make sure that participants' reading comprehension performance would not be affected by internal factors such as anxiety, impatience, etc., there was no specific time limit for this test.

\subsection{Data Collection}

As for scoring, only the second section (English reading comprehension) was counted. We adopted a hundredpercentage point system. Since there were 20 choice questions in total, every question scored 5 points. The results were presented in Table 1. (All the test papers and questionnaires turned to be valid.)

\begin{tabular}{l|l|l|l|l|l|l}
\hline \multicolumn{2}{l}{$\begin{array}{l}\text { Participant } \\
\text { Number }\end{array}$} & \multicolumn{2}{|l|}{ Test Scores } & \multicolumn{2}{l|}{$\begin{array}{l}\text { Scores of } \\
\text { Expository Passages }\end{array}$} & \multicolumn{2}{l}{$\begin{array}{l}\text { Scores of } \\
\text { Narrative Passages }\end{array}$} \\
\cline { 2 - 7 } & EG & CG & EG & CG & EG & CG \\
\hline 01 & 95 & 75 & 45 & 40 & 50 & 35 \\
\hline 02 & 85 & 60 & 45 & 35 & 40 & 25 \\
\hline 03 & 85 & 65 & 50 & 35 & 35 & 30 \\
\hline 04 & 80 & 75 & 45 & 40 & 35 & 35 \\
\hline 05 & 100 & 60 & 50 & 35 & 50 & 25 \\
\hline 06 & 85 & 60 & 50 & 30 & 35 & 30 \\
\hline 07 & 75 & 70 & 40 & 35 & 35 & 35 \\
\hline 08 & 95 & 65 & 50 & 25 & 45 & 40 \\
\hline 09 & 85 & 80 & 35 & 30 & 50 & 50 \\
\hline 10 & 90 & 100 & 45 & 50 & 45 & 50 \\
\hline
\end{tabular}

Besides, as for the questionnaire, participants' answers to each question were computed through the hundred percentage point system. The percentage of each choice in every single question was calculated with the formula:

$\mathrm{P}=\mathrm{P}(\mathrm{A} / \mathrm{B}) \times 100 \%$

where $\mathrm{P}$ was the percentage of each choice in every single question. A represented the number of participants who selected this choice. B referred to the total number of participants. Here B equaled to 20 since there were 20 participants in this experiment. For instance, if five participants choose A in the first question, then the percentage of choice A should be $25 \%$.

Figure-1. Mean test scores of two groups

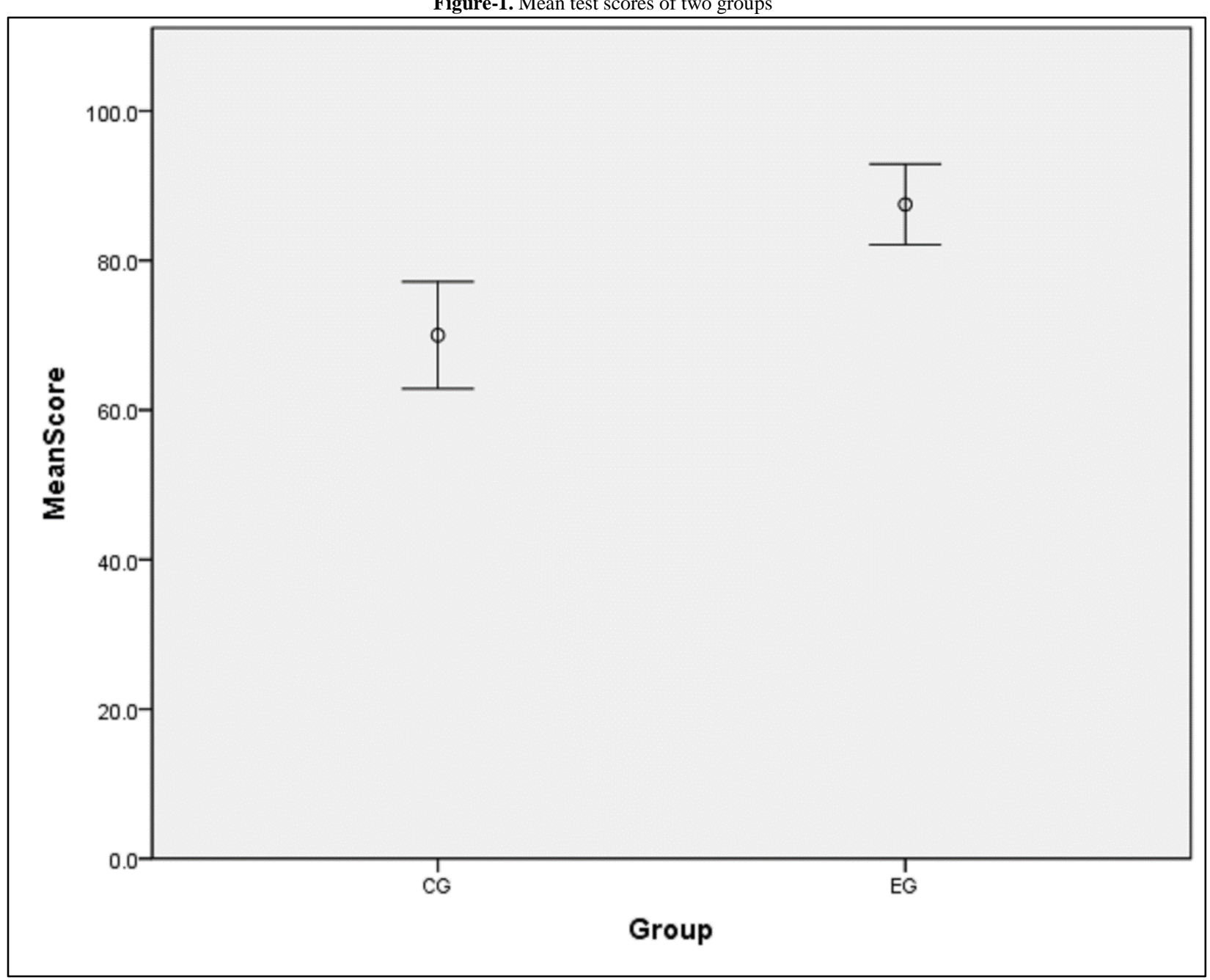




\section{Results}

\subsection{Test Scores}

First, the average test scores of the two groups were counted. The average test score of the experimental group was $87.5(\mathrm{SD}=7.55)$ while that of the control group was $71(\mathrm{SD}=12.42)$. As shown in Figure 1 , the experimental group performed better than the control group.

The test scores of two groups were further analyzed by independent samples t-test with the help of SPSS. Since Sig. which equaled 0.002 was less than 0.05 , there seemed to be significant difference between the scores of two groups. Participants in experimental group had achieved a greater success than those in the control group did. Thus, we inferred that background knowledge has positive effects on Chinese English learners' reading comprehension performance.

\subsection{Scores of Expository and Narrative Passages}

As is shown in Figure 2, the mean score of expository passages of the experimental group was $45.5(\mathrm{SD}=4.97)$ while that of the control group was $35.5(\mathrm{SD}=6.85)$. Independent samples t-test was employed to analyze the scores of expository passages of the experimental group and control group as well. Results (sig. =0.002) showed that significant difference existed between the scores of expository passages of two groups.

Figure-2. Mean test scores of expository passages of two groups

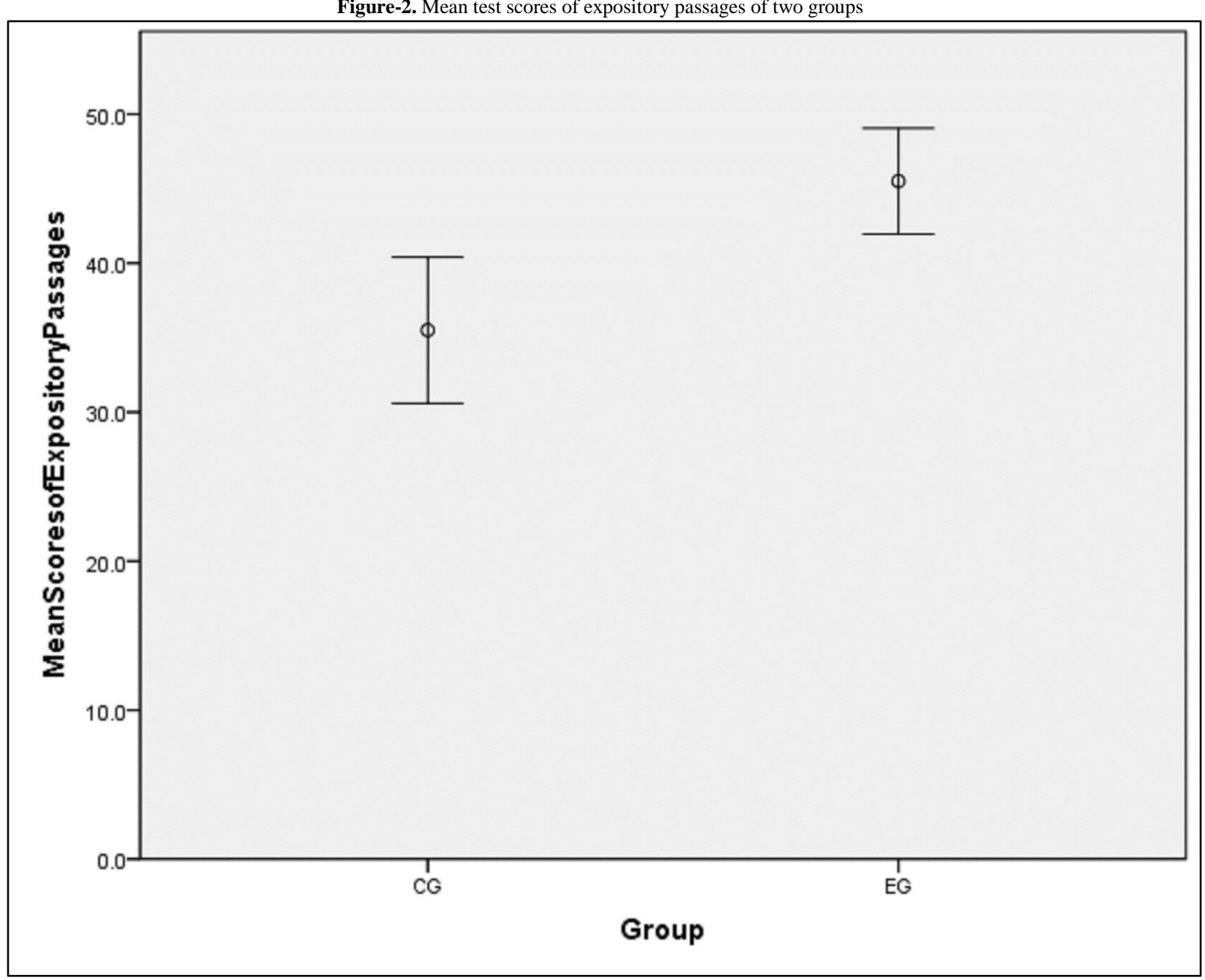

As for expository passages, the mean score of expository passages of the experimental group was 42 while that of the control group was 35.5 (see Figure 3). It seemed from mean scores that the experimental group performed better than the control group on narrative passages. However, through Independent samples t-test, it was found that there was no significant difference between the scores of narrative passages of the two groups. 


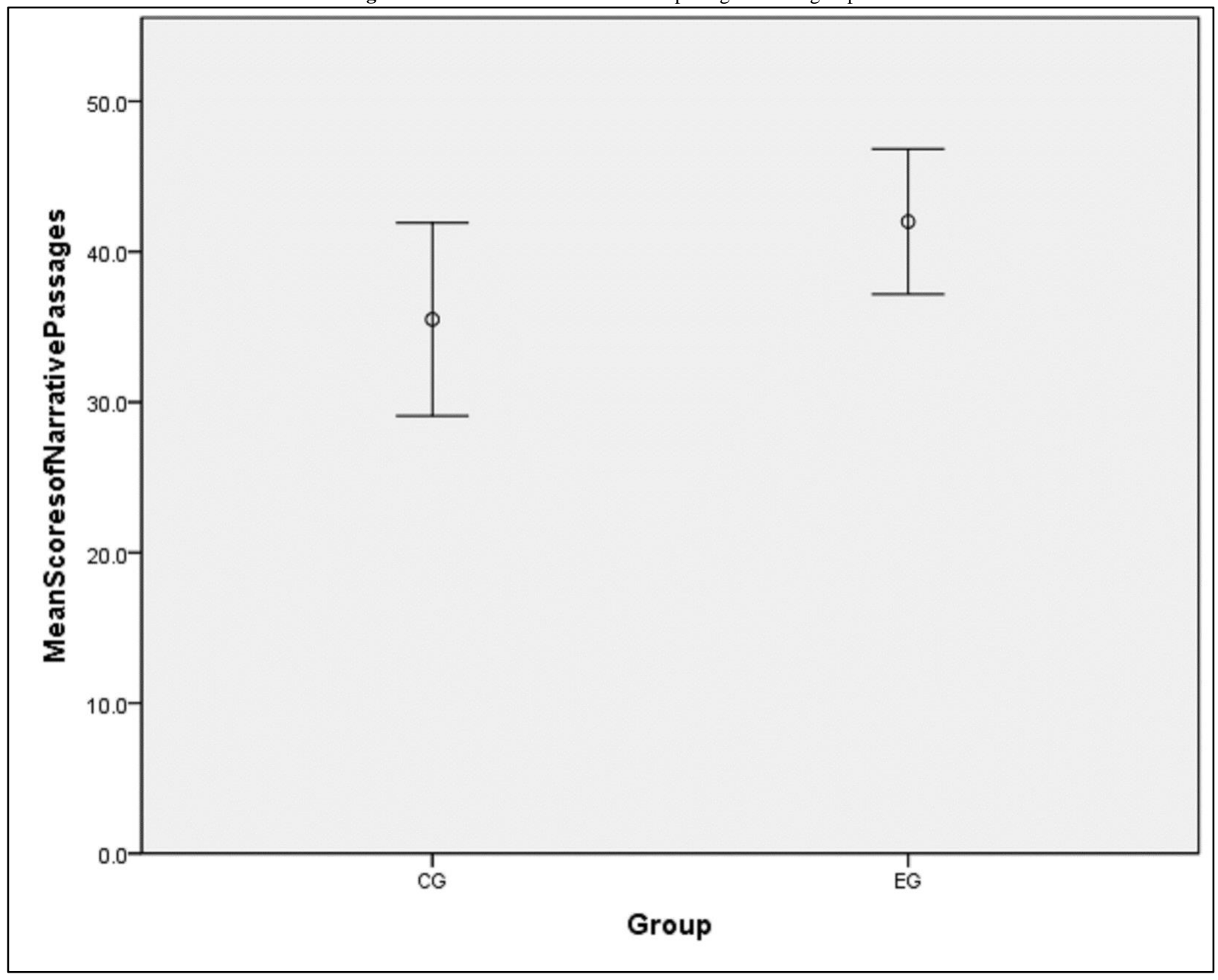

Based on these analyses, the experiment group achieved a greater success in reading and comprehending expository passages than the control group did. However, there seemed to be no difference between their performance on narrative passages. Content schemata seemed to have positive effects on reading comprehension of expository passages and have no effects on that of narrative passages.

\subsection{The Correlation Between Language Proficiency and Reading Comprehension Performance}

In order to answer the question whether the success of reading comprehension is related to language proficiency and whether the insufficiency of language proficiency can be made up by background knowledge, Pearson Correlation was employed. Since Pearson Correlation coefficient equaled 0.077, there was a positive correlation between language proficiency and reading comprehension performance. However, since Sig. $(=0.748)$ was larger than 0.05 , the correlation was insignificant.

In the meantime, we noticed that the test scores of the first and the eighth samples in experimental group $(=95$, $95)$ whose scores in $\operatorname{NMET}(=127,116)$ are lower than the mean value $(=127.6)$ are above the mean value $(=87.5)$. Based on their performance, we come to a conclusion that poor language proficiency does not signify poor performance on reading comprehension. Insufficiency of language proficiency can be made up by background knowledge, which is in accordance with Stanovich's interactive-compensatory model.

\subsection{Results of Questionnaire}

The percentage of every choice in each question was summed in Table 2. It could be observed that these participants tended to employ language knowledge and strategic skill in reading comprehension. Most of them did not realize the important role of background knowledge in English reading comprehension. They were short of the awareness of utilizing content schemata. 
Table-2. A summary of questionnaire results

\begin{tabular}{|c|c|}
\hline Questions & Percentage \\
\hline \multicolumn{2}{|l|}{ 1. What is the main factor affecting reading comprehension? } \\
\hline A. Background knowledge & $25 \%$ \\
\hline Language proficiency & $75 \%$ \\
\hline C. $\quad$ Text type & $0 \%$ \\
\hline \multicolumn{2}{|l|}{ 2. How do you read? } \\
\hline $\begin{array}{l}\text { A. To comprehend the general idea, supporting details and author's intended } \\
\text { meaning by making use of language knowledge and reading skills. }\end{array}$ & $75 \%$ \\
\hline To read word by word carefully and try to comprehend every detail. & $15 \%$ \\
\hline $\begin{array}{l}\text { C. To understand the general idea by recalling known background } \\
\text { knowledge. }\end{array}$ & $10 \%$ \\
\hline \multicolumn{2}{|l|}{ 3. What is your reading comprehension process? } \\
\hline $\begin{array}{l}\text { A. An active process of making assumptions, analyzing, summarizing and } \\
\text { reasoning. }\end{array}$ & $45 \%$ \\
\hline A process of receiving information in a passive way. & $5 \%$ \\
\hline A process of reading questions and searching for key words busily. & $50 \%$ \\
\hline
\end{tabular}

\section{Discussion}

The current study investigated the influence of content schemata on Chinese English learners' performance in reading comprehension. Participants at the same English level were tested through a specially designed reading comprehension test. In this section, three research questions and experiment results are discussed.

As to the first question, the results showed that content schemata indeed had an effect on Chinese English learners' reading comprehension performance. This finding is in accordance with previous studies (Huang, 2012; Qi and Wang, 1988; Zhang, 2004). Reading is a psycholinguistic guessing game rather than a simple process of decoding linguistic clues (Goodman, 1967). Readers always play an active role. To reveal how readers making use of content schemata in the light of schema theory, let's take the second passage as an example. The topic of it was otitis media. Participants in the experiment group could firstly develop a schema about it through reading the Chinese excerpt. They could realize that otitis media is a middle ear infection which often occurs in children. Then they formulated some hypotheses according to this schema. After that, they read to ensure whether the text confirmed those hypotheses or not. If the hypotheses were confronted with difficulties or contradictories, they checked back to see what the divergence was. The schema of otitis media led participants in experiment group to a right way of comprehension and increased their reading efficiency. Based on the results, we come to the conclusion that background knowledge contributes to English reading comprehension. The more schemata a reader possesses, the greater success he will achieve in English reading comprehension.

The scores of expository and narrative passages were also analyzed to see whether content schemata have different effects on different text types. Results showed that content schemata enhanced the performance on expository passage comprehension while it had few effects on narrative passage comprehension. Carrel (1984), posits that every narrative passage has its own logic. A reader is capable of comprehending the text with the help of its structure on the premise that he is able to discern its logic. Carroll (2000), believes that every narrative passage has a story grammar, i.e. story schema. Stored in long-time memory, a story schema contains the sequence of events. For narrative passages, story schemata should be more helpful.

Both the two groups' reading performance on narrative passages were not good. Rumelhart (1981), has mentioned three possible causes of incorrect or inadequate comprehension of a text: 1) lack of relative schemata; 2) insufficient clues provided by the text; and 3) a seemingly coherent explanation of the text which is totally deviates from the author's intended meaning. Among these three factors, what is the main cause of participants' poor performance on narrative passages? It is shown that for Asians, texts with problem-solution or causation structures are recalled best, while texts with comparison structures or descriptions are recalled least well (Carrel, 1984). Meanwhile, he also discovered that only 1/4 L2 learners can activate their formal schemata. Therefore, the lack of relevant story schemata may lead to Chinese English learners' poor reading performance on narrative passages. Further evidence is needed to prove this deduction.

Besides, this experiment also proved that reading comprehension performance was related to language proficiency. Poor language proficiency did not signify poor performance on reading comprehension. As is proposed by Stanovich (1980), a reader's language knowledge and background knowledge interact and compensate each other. In this experiment, it was proved that content schemata could contribute to the comprehension of expository passages.

Based on the above, the study has some pedagogical inspirations for English teaching and learning. Teachers should focus on not only the cultivation of students' language knowledge, but also the expansion of different types of schemata. As for Chinese English learners, they should attach great importance to the accumulation of background knowledge and improve their reading method Reading texts of the same topic together is conducive to the improvement of reading comprehension ability. 


\section{Conclusion}

This study examined the influence of content schemata on Chinese English learners. Results showed that content schemata were conducive to the performance on the comprehension of expository passages. However, participants generally lacked the awareness of utilizing content schemata according to the questionnaire. Some suggestions about English learning and teaching were thus provided.

This research inevitably had some limitations. First, participants were limited to a small group of college students. Second, other types of schemata were not investigated. In the future, researchers may take more samples from different groups and employ more effective forms to investigate the influence of more types of schemata on Chinese English learners' reading comprehension performance.

\section{Acknowledgements}

The author thanks all the participants, and her beloved supervisor, parents as well as friends for their support.

\section{References}

Afflerbach, P. (1990). The influence of prior knowledge on expert readers' main idea construction strategies. Reading Research Quarterly, 25(1): 31-26.

Barlett, F. C. (1932). Remembering, A study in experimental and social psychology. Cambridge University Press: Cambridge.

Caroline, A. C. (1996). The development of IELTS, A study of the effects of background knowledge on reading comprehension. Cambridge University Press: Cambridge.

Carrel, P. L., 1981. "Culture-specific schemata in L2 comprehension." In Selected Papers from the Ninth Illinois TESOL Annual Convention, the First Midwest TESOL Conference, eds. R. Oren and J. Haskell, Chicago: Illinois TESOL.

Carrel, P. L. (1984). Schema theory and ESL reading, Classroom implications and applications. Modern Language Journal, 68(4): 332-43.

Carrel, P. L. and Eisterhold, J. C. (1983). Scheme theory and ESL reading pedagogy. TESOL Quarterly, 17(4): 55373.

Carroll, D. W. (2000). Psychology of language. Foreign Language Teaching and Research Press: Beijing.

Goodman, K. S. (1967). The psycholinguistic nature of the reading process. Detroit Wayne State University Press: Detroit.

Harris, A. J. and Sipay, E. R. (1975). How to increase reading ability. 6th edn: David McKay Company: New York.

Huang, X. Y. (2012). An investigation into the effects of background knowledge intervention on English reading compression`. Doctoral Dissertation. China: Zhejiang University.

Johnson, P. (1981). Effects on reading comprehension of language complexity and cultural background of a text. TESOL Quarterly, 15(2): 169-81.

Piaget, J. (1926). The language and thought of the child. Routledge and Kegan Paul: London.

Qi, L. X. and Wang, C. M. (1988). Background knowledge and language complexity in reading comprehension. Foreign Language Teaching and Research, 74(2): 24-30.

Reber, A. S. and Reber, E. (2001). The penguin dictionary of psychology. 3rd edn: Penguin Books Ltd: London.

Rumelhart, D. E. (1981). Schemata, The building blocks of cognition. In Comprehension and Teaching, Research Reviews, ed. J. T. Guthrie. International Reading Association: Newark Delaware.

Rumelhart, D. E. and Ortony, A. (1977). The representation of knowledge in memory. In Schooling and the Acquisition of Knowledge, eds, R.C. Anderson. Lawrence Erlbaum Associates: New Jersey.

Schmid-Rinehart, B. C. (1994). The effects of topic familiarity on second language listening comprehension. Modern Language Journal, 78(2): 179-89.

Stanovich, K. E. (1980). Toward an interactive-compensatory model of individual differences in the development of reading fluency. Reading Research Quarterly, 16(1): 32-71.

Widdowson, H. G. (1983). Learning purpose and language use. Oxford University Press: Oxford.

Zhang, Y. Q. (2004). Effects of background knowledge on foreign language reading comprehension. Journal of Fujian Agriculture and Forestry University, Philosophy and Social Sciences, 7(4): 74-77. 